\title{
A Heuristic Approach for Distributing Pilgrims over Mina Tents
}

\author{
Mohd K. Shambour and Esam Khan \\ The Custodian of the Two Holy Mosques Institute for Hajj and Umrah Research, Umm Al Qura \\ University, Makkah, Saudi Arabia \\ myshambour@uqu.edu.sa
}

\begin{abstract}
Every year, more than two million Muslims come to the holy city, Makkah, to perform Hajj (the Islamic pilgrimage). One of Hajj rituals is to spend two to three nights in Mina, one of the holy sites. Distributing Muslim pilgrims in Mina, respecting different kinds of constraints, over limited number of tents is a real-world optimization problem. In this paper, a heuristic based algorithm is proposed, called Mina Tent Distribution Algorithm (MTDA), attempting to better utilize the available capacity of Mina's area in the best possible way with an efficient use of the available resources. MTDA employs seven functions during the search process to find the best fit accommodation for pilgrims on the available tents of Mina. Experimental results revealed that MTDA achieves better performance compared with eight algorithm schemes in all experimental cases. The best result of MTDA was obtained through allocating $80 \%$ of the total number of pilgrims over $76.2 \%$ of the total available accommodation space of Mina area.
\end{abstract}

Keywords: Hajj rituals, Distributing, Constraints, Heuristic.

\section{Introduction}

Annually, more than two millions of people reach Makkah, in Saudi Arabia, to perform the fifth pillar of Islam "Hajj". Hajj is an Islamic ritual starting on the 8th day of the lunar month Dhu al-Hijjah (the $12^{\text {th }}$ month of the Islamic calendar) and ends on the $13^{\text {th }}$ day of Dhu al-Hijjah ${ }^{[1]}$. Mina is one of the hajj sites in which pilgrims must spend some times. Therefore, it is considered as one of the most important places for pilgrims during Hajj season, because pilgrims must spend two to three nights in Mina's tents and throw stones at Al-Jamarat building seven or ten times.

According to the General Authority for Statistics (2019) ${ }^{[2]}$, the number of pilgrims was 2.371.675 in the last Hajj season (2018), and the available space that is dedicated for housing pilgrims in Mina is 2.642.752 square meters ${ }^{[3]}$. This poses a challenge of how to accommodate the maximum number of pilgrims in Mina tents while preserving the maximum level of comfort.

Although there are attempts to improve Mina's capacity using new architectural designs in order to augment the number of pilgrims in the future ${ }^{[4]}$, the process of distributing groups of pilgrims over the current limited number of tents is a real-world optimization problem that needs a solid heuristic method.

According to the best knowledge of the authors of the present study, this is the first work that attempts to optimize the distribution process of groups of pilgrims through introducing a heuristic-based approach that is 
able to efficiently use the available resources while satisfying all existing constraints.

In the proposed algorithm, different functions were employed to allocate pilgrims' groups into Mina tents. During the search process, the groups of pilgrims are assigned to the best fit accommodation (e.g. a single tent, a part of a tent, or more than a tent). Different scenarios were examined to ensure the validity and stability of the proposed algorithm. The simulation results demonstrated that the proposed algorithm can provide efficient and satisfactory distribution results for Mina tents.

The rest of the paper is organized as follows. Section 2 provides the related works. Problem description is given in section 3 . Proposed approach and experimental results are presented in section 4 and section 5, respectively. Finally, conclusion and future work are given in section 6 .

\section{Related Works}

The distribution process of pilgrims over the available tents in Mina with respect to the defined constraints is similar to the resource allocation problems. It is to observe the optimal distribution of a number of defined resources to activities whilst optimizing the cost incurred by the distribution process ${ }^{[5,6]}$. Resource allocation problems have been presented in many research fields and applications, such as cloud computing, wireless networks, task resource allocation, and robot system.

Reichman et al. (2018) [7] applied a greedy color assignment and a random $\mathrm{k}$ coloring algorithms to optimize the resources of wireless mesh network systems. The authors aimed to efficient utilization of network resources and allow the frequency to be reused. In the same context, Maleki and Mirjalily (2019) ${ }^{[8]}$ presented a cross layer model for effective exploiting of wireless network resources using a genetic algorithm.
The proposed model maximizes the efficiency through optimizing the use of power control, routing, channel selection and assignment, adaptation of rate, and scheduling.

Nguyen et al. (2018) [9] applied the resource allocation algorithm in fog computing system instead of cloud system to minimize the latency caused. The user applications are divided into modules in order to be processed on fog nodes. The proposed algorithm was applied on iFogSim toolkit simulator ${ }^{[10]}$ to model and simulate the proposed fog computing. In another research, Santos et al. (2019) ${ }^{[11]}$ proposed a heuristic algorithm to assign resources of cloud, edge devices, and wireless sensors to user applications. The proposed algorithm is designed to execute common tasks requested by user applications only once and sharing the results back. Also, the proposed architecture supported the response time to the sensitive applications.

Additionally, Gülpına et al. (2018) [12] applied a construction heuristic method for task resource allocation problem. Two cases for the assignment process are tackled. First, if the task assignment process is failed, then the method will give another assignment chance for failed assignment at later period. Second, if the process is successfully assigned, then the allocated resource can be reused to allocate other tasks, assuming the best use of the resources. Lee (2018) ${ }^{[13]}$ introduced an auction-based algorithm to decrease the waste time and resources spent during robot operations. The algorithm provides an estimation for the required task performance of robot considering the resource level of refill stations. Moreover, Sun et al. (2017) [14] proposed an evolutionary game theoretic approach to find the best resource allocation in multi-agent systems. Authors applied a distributed algorithm based on local replicator dynamics to design the distributed allocation mechanism, such that all individuals update their resources according to the local average. 
According to the above review of previous literatures, there are many approaches that are used to solve various resource allocation problems. Meanwhile, there is a lack of studies that addressed the distribution process in Mina area. Therefore, in this paper, a heuristic approach is applied to optimize the distribution process of groups of pilgrims over Mina tents while satisfying all existing constraints as much as possible.

\section{Problem Description}

The assigning process of pilgrims groups to their tents is a discrete search space problem, where one has to find the perfect feasible permutation that satisfies allocating of all pilgrims groups to a limited number of tents.

\subsection{Data Attributes}

Table 1 shows the total number of pilgrims according to the pilgrims' countries in $2018^{[4]}$. Each country group (CG) has a number of pilgrims groups (PGs) that share similar features such as nationality, reservation class, etc. In this research, the number of PGs for all CGs is set to 587. For each PG, a random number of pilgrims was assigned starting from 500 and up to 5,000. Table 2 provides an example for the assignment procedure of PGs.

Table 1. Pilgrims by CGs ${ }^{[4]}$.

\begin{tabular}{|l|c|}
\hline \multicolumn{1}{|c|}{ Domestic and foreign Pilgrims } & $\begin{array}{c}\text { Number of } \\
\text { Pilgrims }\end{array}$ \\
\hline Domestic pilgrims & 612,953 \\
\hline Arab pilgrims & 429,550 \\
\hline Asian pilgrims (non-Arab) & $1,049,496$ \\
\hline African pilgrims (non-Arab) & 166,083 \\
\hline European pilgrims & 88,601 \\
\hline $\begin{array}{l}\text { North and south America, and } \\
\text { Australia pilgrims }\end{array}$ & 24,992 \\
\hline Total & $\mathbf{2 , 3 7 1 , 6 7 5}$ \\
\hline
\end{tabular}

Table 2. An example for African pilgrims (non-Arab).

\begin{tabular}{|c|c|}
\hline PGs & Number of Pilgrims \\
\hline Group 1 & 1,005 \\
\hline Group 2 & 600 \\
\hline Group 3 & 4,002 \\
\hline$\cdot$ & $\cdot$ \\
\hline$\cdot$ & $\cdot$ \\
\hline Group n & 2,222 \\
\hline Total & $\mathbf{1 8 8 , 6 2 4}$ \\
\hline
\end{tabular}

Accordingly, the main components of data input attributes for the taken problem is designed as given in Table 3.

Table 3. PG Attributes.

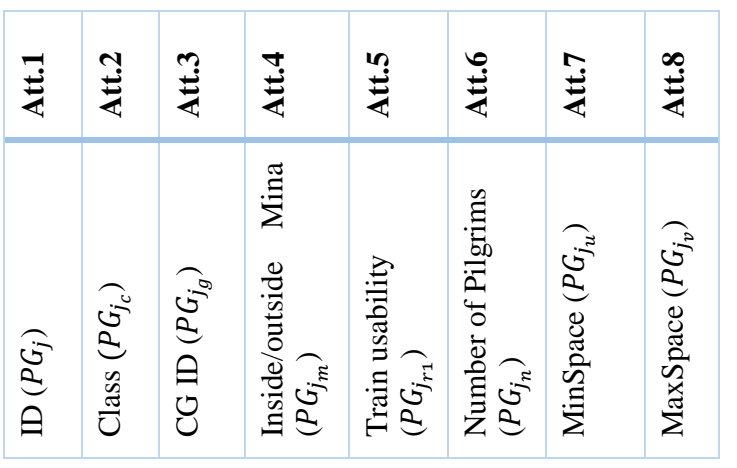

The "Class" attribute refers to a reservation class, which is used to assign PGs to tents that belong to their reserved class. The attribute "Inside/outside Mina" refers to the location of the tent, i.e. tent is either located in Mina or Mozdalifa. Mozdalifa is a valley that is half way between Mina and Arafat. "Train usability" attribute refers to the ability $(r l=1)$ or inability $(r l=0)$ to use the train by pilgrims. "MinSpace" and "MaxSpace" attributes are the minimum and maximum available space (in square meters) for each PG, respectively.

On the other hand, the Mina area is split into 230 blocks of tents, each of which has a random number of tents up to 10 tents per block. Furthermore, each tent has a random space starting from $100 \mathrm{~m}^{2}$ and up to $5,000 \mathrm{~m}^{2}$. 
Figure 1 provides an example for the basic structure of Mina, whereas Table 4 shows the basic tent attributes.

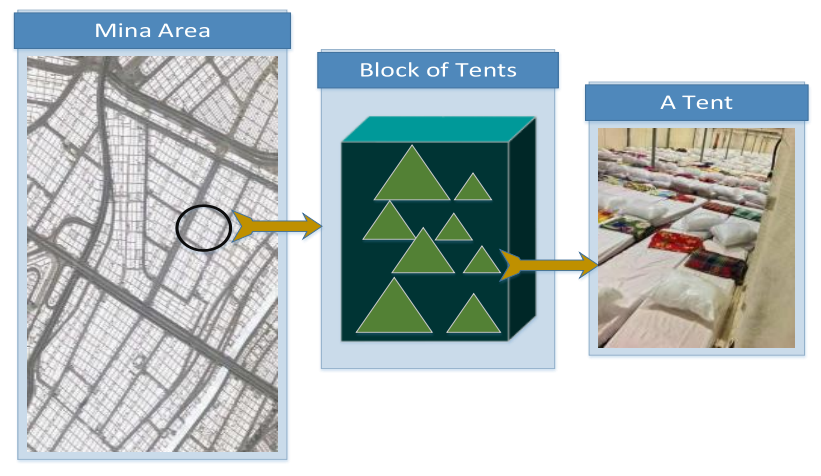

Fig. 1. Basic Structure of Mina.

Table 4. Tent (T) Attributes.

\begin{tabular}{|l|l|l|l|l|l|}
\hline Att1 & Att2 & Att3 & Att4 & Att5 & Att6 \\
\hline Tent & Block & Class & Inside/outside & Train & Space \\
ID & ID & $\left(T_{i_{c}}\right)$ & Mina & usability & $\left(T_{i_{s}}\right)$ \\
$\left(T_{i}\right)$ & $\left(T_{i_{b}}\right)$ & & $\left(T_{i_{m}}\right)$ & $\left(T_{i_{r 2}}\right)$ & \\
\hline
\end{tabular}

The "Block ID" attribute mentioned in Table 4 denotes the block number that the tent is belongs to. "Space" attribute refers to the available space dedicated to housing pilgrims. Train usability refers to the location of the tent with respect to train stations. If the tent is close to train station, $r 2=1$. Otherwise $r 2=0$. The other attributes are similar to those in $P G$ attributes, however they are dedicated to tent instead of PG.

\subsection{Objective Function and Problem Constraints}

The objective function is defined to evaluate the quality of feasible solutions of the problem being solved, such that the optimal solution is the solution that has the best value obtained by the objective function, considering the given constraints.

In this study, the optimal solution can be satisfied through distributing all group of pilgrims over the available tents in Mina area. So that, the objective function is defined as maximizing the number of PGs that need to be assigned to Mina tents, which can be stated as follows:

- Maximize (assigning PGs to tents), such that all constraints are fulfilled.

The current problem defines nine major constraints, and the mathematical formulation is given below:

- Assignment $(A)$ is a function of resources $(P G, T)$, such that the problem constraints $(C 1, C 2, \ldots, C 9)$ can be mathematically represented as:

C1: Each group of pilgrims must be assigned once.

$$
A_{P G}^{T}=A_{P G_{j}}^{T_{i}} \quad \forall i \in T, j \in P G
$$

C2: Two groups of pilgrims cannot be assigned to the same tent.

$$
\begin{aligned}
& A_{P G_{j}}^{T_{i}} \neq A_{P G_{k}}^{T_{i}} \\
& j \neq k, \forall i \in T, \forall j \in P G, \forall k \in P G
\end{aligned}
$$

C3: The available space for each tent must be adequate to the number of assigned pilgrims.

$$
A_{P G_{j_{u}}}^{T_{i}} \leq A_{P G_{j_{s}}}^{T_{i}} \leq A_{P G_{j_{v}}}^{T_{i}}
$$

where $P G_{j_{s}}$ is the allocated space for

$$
P G_{j}, \forall i \in T, \forall j \in P G
$$

C4: Predefined tents must not be violated (e.g. medical clinics and police stations blocks must not be used to allocate pilgrims).

$$
A_{P G_{j}}^{T_{v}}=\varnothing
$$

where $T_{v}$ is a Predefined tent, $\forall j \in P G$

C5: Each tent should be fit to its allocated pilgrims group.

$$
A_{P G_{j}}^{T_{i}}=A_{P G_{j q}}^{T_{i_{s}}}
$$

where $P G_{j_{q}}$ is the allocated space for $P G_{j}$, 


$$
T_{i_{s}}-P G_{j_{q}} \cong 0, \forall j \in P G, i \in T
$$

C6: Similar groups of pilgrims in terms of country group should be beside each other.

$$
\begin{gathered}
A_{P G_{j_{g}}}^{T_{i_{b}}}=A_{P G_{l_{g}}}^{T_{k_{b}}} \\
i \neq k, j \neq l, \forall i \in T, \forall j \in P G, l \in P G
\end{gathered}
$$

C7: Similar pilgrims groups in terms of transportation facilities who used train should be allocated to certain tents that are close to train station.

$$
\begin{gathered}
A_{P G_{j}}^{T_{i}}=A_{P G_{j_{r 2}}}^{T_{i_{r 1}}} \\
r 1=r 2, \quad \forall i \in T, \forall j \in P G
\end{gathered}
$$

C8: A group of pilgrims should be assigned to a tent belonging to the class they reserved.

$$
\begin{gathered}
A_{P G_{j}}^{T_{i}}=A_{P G_{j_{c_{n}}}}^{T_{i_{c_{m}}}} \\
n=m, \forall i \in T, \forall j \in P G
\end{gathered}
$$

C9: A group of pilgrims should be assigned to a tent belonging to the same block or at most to two adjacent blocks.

$$
\begin{aligned}
& A_{P G_{j}}^{T_{i_{b_{m}}}}=A_{P G_{j}}^{T_{i_{b_{n}}}}\left|T_{i_{b_{m}}}-T_{i_{b_{n}}}\right|=\{0,1\}, \\
& n=m, \forall i \in T, \forall j \in P G
\end{aligned}
$$

\section{Proposed Approach}

In this research, a constructive heurist algorithm, called Mina Tent Distribution Algorithm (MTDA), is designed based on the idea of allocating groups of pilgrims into the best fit place in Mina tents. The following subsections provide descriptions of the used allocation schemes by MTDA and the main steps of MTDA.

\subsection{Constructive Allocation Schemes}

The proposed MTDA employs eight allocation schemes to build a complete solution at the end of each run. The explanations of the introduced schemes are given as follows:

- BlockFit (BF): Where a group of pilgrims is to be fitted to all tents belonging to a single block, respecting the problem constraints.

- TwoBlockFit_1 (TBF1): Where a group of pilgrims is to be fitted to all tents belonging to two adjacent blocks, respecting the problem constraints.

- Part-blockFit (PF): Where a group of pilgrims is to be fitted to some tents belonging to a single block, respecting the problem constraints.

- TwoBlockFit_2 (TBF2): Where a group of pilgrims is to be fitted to two adjacent blocks, such that all tents in the first block and some tents of the second block are taken, respecting the problem constraints.

- TwoBlockFit_3 (TBF3): Where a group of pilgrims is to be fitted to two adjacent blocks, such that some tents of the first block and some of the second block are taken, respecting the problem constraints.

- ElasticBlockFit (EBF): Where a group of pilgrims is to be fitted to all tents belonging to a single block but with some space left, respecting the problem constraints.

- ElasticPart-blockFit (EPF): Where a group of pilgrims is to be fitted to some tents belonging to a single block with some space left, respecting the problem constraints.

- PriorityFit (PrF): Where a group of pilgrims will be assigned to a tent or group of tents using one of the above algorithms in a predefined order (as it is ordered above). The aim is to minimize the left space as much as possible. For example, if the first algorithm scheme (i.e. BF) fails in assigning a group of 
pilgrims to a tent, then the second algorithm scheme (i.e. TBF1) will take place, and so on.
Figure 2 provides an example of using each of the schemes mentioned above.

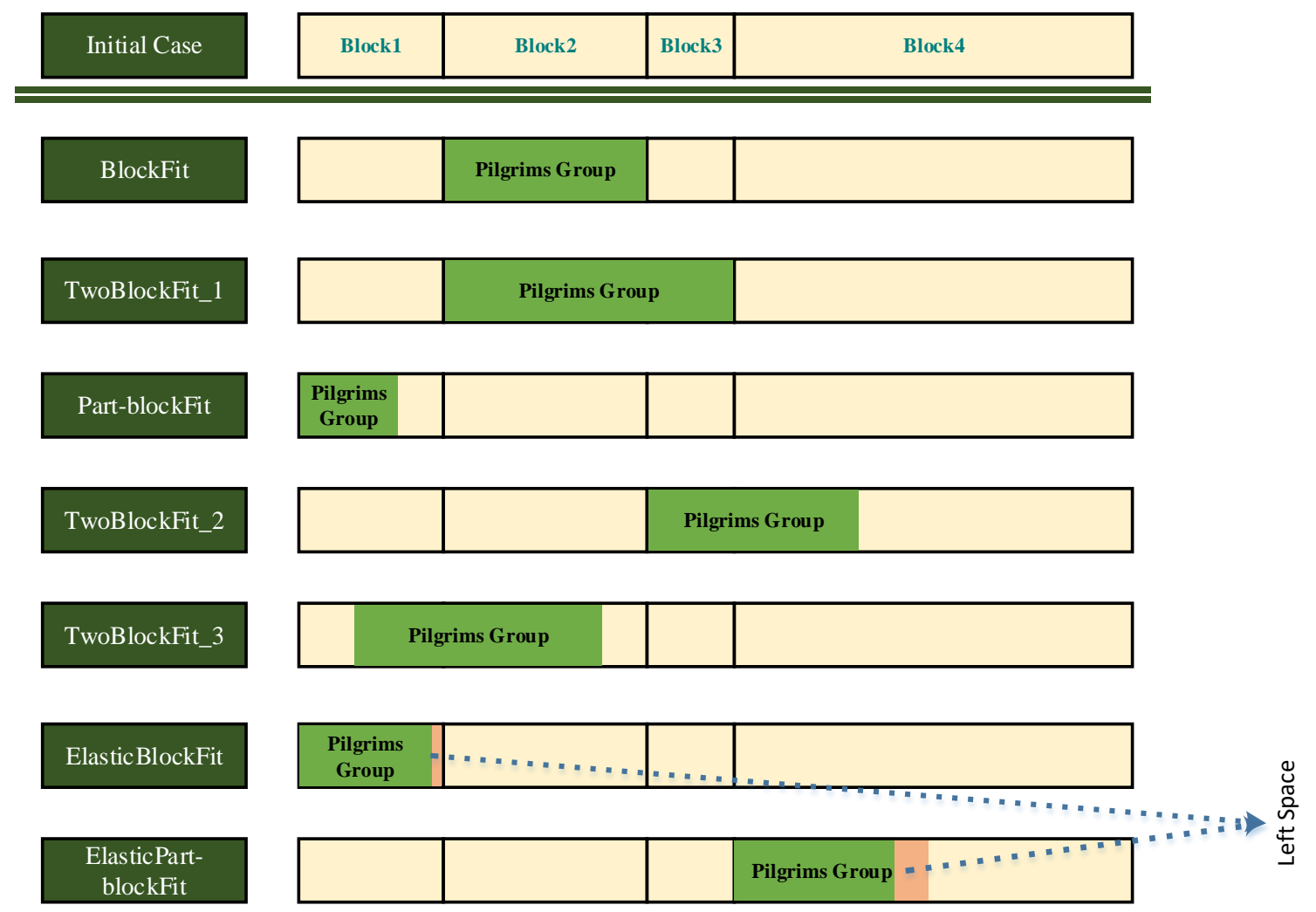

Fig. 2. Examples of applying the proposed allocation schemes.

\subsection{Steps of the Proposed Approach}

The main steps of the MTDA that describe the proposed algorithm are listed below:

\section{Step1. Initialization}

In this step, the algorithm and problem parameters are set. These parameters are the maximum number of iterations (MaxItr), the number of PGs per $\mathrm{CG}$, the number of pilgrims per $\mathrm{PG}$, the class of $\mathrm{PG}$, the available tents per block, the available tent space and location, MinSpace, MaxSpace, allowable left space ratio in distribution (LeftSpaceRate), and train usability.

\section{Step 2. Building a new solution}

The algorithm starts by iteratively providing all the available and suitable tents in Mina blocks for each PG in every CG. After that, one of seven allocating functions $(f)$ accompanying with its parameters is randomly selected to find the best-fit tent in Mina block for the taken PG. If the chosen function fails to obtain an appropriate tent, the PG is classified into the undistributed groups and it will take another distribution chance in the next iterations. This step is repeated until the stopping criteria of the algorithm is met. The allocation functions $(f)$ applied in the proposed MTDA are: BF, TBF1, PF, TBF2, TBF3, EBF, and EPF. 
Step 3. Best alternative update

If the algorithm finds a better solution, in terms of distributing groups of pilgrims over available capacity of Mina, compared to the previous solution, the old solution will be replaced by the new solution.

Step 4. Stopping the algorithm

Three conditions were proposed to stop the algorithm, which are:

- No more groups are unallocated,

- No better solution is observed in a 10 subsequent iterations for every run, or

- Reaching the maximum number of iterations (MaxItr).

The pseudocode and flowchart of the MTDA are given in Algorithm 1 and Fig. 3 respectively.

\section{Experimental Results}

The performance of the proposed MTDA designed to solve the allocation problem are compared with the performance achieved by eight algorithm schemes, BF, TBF1, PF, TBF2, TBF3, EBF, EPF, and PrF.

\subsection{Experimental Settings}

Various combinations of problem parameters values were investigated to test and validate the algorithm efficiency, and to ensure the usability of the MTDA. Therefore, a series of experiments with different algorithm parameters along with different input scenarios are performed. The scenarios that are used for comparisons are given in Table 5.

Algorithm 1. Pseudocode of the MTDA.

Step 1. Initialization: Initialize MTDA parameters including train usability, MinSpace, MaxSpace, LeftSpaceRate, MaxItr, PGs per CG, Tents, etc.

Step 2. Building a new solution (Sol"):

For each $g \in(1$, number of $\mathrm{CG})$ do

For each $\mathrm{j} \in\left(1\right.$, number of $P G$ s in $\left.\mathrm{CG}_{\mathrm{g}}\right)$ do

$\{$ CandidateTents $\}=$ find (AvailableTents, $\mathrm{PG}_{\mathrm{j}}$, Class, trainusability, MinSpace, MaxSpace) \returns all Candidate tents for $P G_{j}$

$\mathrm{NF}=$ rand $(1,7) \backslash$ select a random allocation function

If $f_{N F}\left(\{\right.$ CandidateTents $\}, \mathrm{PG}_{\mathrm{j}}$, LeftSpaceRate $) \backslash *$ i.e.Check whether the $P G_{j} c a n$ be assigned to a tent of AvailableTents (note that LeftSpaceRate parameter is used only in $f_{6}$ and $\left.f_{7}\right) * 1$

Allocate $\mathrm{PG}_{\mathrm{j}}$ to CandidateTents $\mathrm{x} \backslash \mathrm{X} \epsilon$ (1, sizeof (CandidateTents))

$\mathrm{Sol}^{*}=\mathrm{Sol}^{*} \mathrm{U} \mathrm{PG}_{\mathrm{j}} \backslash$ i.e. Add $\mathrm{PG}_{\mathrm{j}}$ to new solution Sol*

Remove CandidateTents ${ }_{\mathrm{x}}$ from \{AvailableTents

Remove $\mathrm{PG}_{\mathrm{j}}$ from $\left\{\mathrm{CG}_{\mathrm{g}}\right\}$

End If

End For

End For

Step 3. Best alternative update

If $\mathrm{h}\left(\mathrm{Sol}^{*}\right)$ better than $\mathrm{h}\left(\mathrm{Sol}_{\text {best }}\right)$

$\mathrm{Sol}_{\text {best }}=$ Sol $^{*}$

End If

Step 4. Stopping the algorithm: Stop if the termination criterion is met; otherwise go to Step 2. 


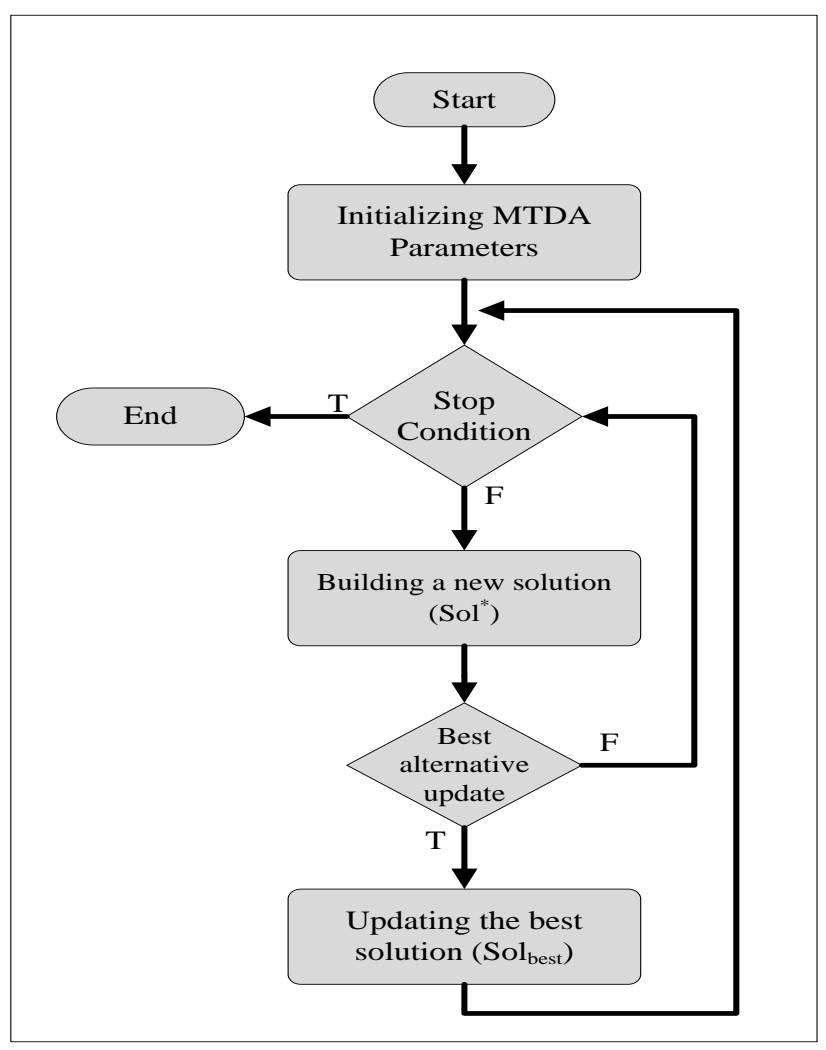

Fig. 3. A flowchart for the proposed MTDA.

Table 5. Experiment Scenarios.

\begin{tabular}{|c|c|c|c|}
\hline Scenarios & $\begin{array}{c}\text { MinSpace } \\
\left.\boldsymbol{m}^{\mathbf{2}}\right)\end{array}$ & $\begin{array}{c}\text { MaxSpace } \\
\left(\boldsymbol{m}^{\mathbf{2}}\right)\end{array}$ & $\begin{array}{c}\text { Flexibi } \\
\text { lity Rate } \\
\left(\boldsymbol{m}^{\mathbf{2}}\right)\end{array}$ \\
\hline $\mathbf{S 1}$ & 1.00 & 1.2 & 0.1 \\
\hline $\mathbf{S 2}$ & 1.00 & 1.2 & 0.2 \\
\hline $\mathbf{S 3}$ & 1.2 & 1.4 & 0.1 \\
\hline $\mathbf{S 4}$ & 1.2 & 1.4 & 0.2 \\
\hline $\mathbf{S 5}$ & 1.4 & 1.6 & 0.1 \\
\hline $\mathbf{S 6}$ & 1.4 & 1.6 & 0.2 \\
\hline
\end{tabular}

The elements of each scenario are MinSpace $\left(\mathrm{m}^{2}\right), \quad$ MaxSpace $\left(\mathrm{m}^{2}\right), \quad$ and Flexibility rate $\left(\mathrm{m}^{2}\right)$. The Flexibility rate is an extra space rate given to a PG that cannot be assigned to any tent in a normal distribution process. (Note that the normal distribution process for all PGs is limited by the defined rates MinSpace and MaxSpace). For example, suppose that the number of pilgrims in $\mathrm{PG}_{1}$ is 5000 pilgrims. For scenario S1, the space (s) of $\mathrm{PG}_{1}$ is bounded by the minimum and maximum spaces, as given below,

$$
5000 m^{2} \leq \mathrm{PG}_{1_{s}} \leq 6000 \mathrm{~m}^{2}
$$

In this case, $\mathrm{PG}_{1}$ must be assigned to a bounded tent size $\left(5000 \mathrm{~m}^{2}-6000 \mathrm{~m}^{2}\right)$. However, this space may not be found in the available tents during the search procedure. In that case, the added flexibility rate will give the search procedure the ability to find a tent with more extra space given to pilgrims in $\mathrm{PG}_{1}$, such that the maximum space given to $\mathrm{PG}_{1}$ will be $6500 \mathrm{~m}^{2}$ instead of $6000 \mathrm{~m}^{2}$.

One experiment is performed for each technique in every scenario. In each experiment, the program runs 30 times with a two stopping conditions: (i) No improvement on the current solution for ten consequent iterations, or (ii) When number of iterations reaches the MaxItr, which is set to 1000. All problem and algorithm parameters are reinitialized in every run. Furthermore, one completed solution (Sol $\left.{ }^{*}\right)$ is built in every run. After the 30 runs, the solution with the highest objective function value is considered the best solution and is called ( Sol $\left._{\text {best }}\right)$.

The experiments are conducted using a computer with processor Intel(R) Core i5@3.4 $\mathrm{GHz}$ with $12 \mathrm{~GB}$ of RAM and 64-bit for Microsoft Windows 10. Matlab version 2016b programming language is used to code the MTDA.

\subsection{Results and Discussion}

Eight algorithm schemes were used to observe the distribution efficiency of the proposed MTDA including BF, TBF1, PF, TBF2, TBF3, EBF, EPF, and PrF schemes.

Every algorithm considers the efficient use of the available space of Mina tents and tries to eliminate the usage of extra given space to pilgrims. Table 6 provides the experimental results for distributing pilgrims per CG (in percentage). Each algorithm scheme was applied on the six different scenarios (given in Table 5) in every CG. So, 
the total number of experiments is 54. The results in Table 6 show that the MTDA achieves $98.5 \%$ better performance compared to the other schemes. Results also show that the $\mathrm{BF}$ and $\mathrm{PF}$ schemes generate similar solutions for the experiments performed on i) scenarios $\mathrm{S} 1$ and $\mathrm{S} 2$, ii) scenarios $\mathrm{S} 3$ and $\mathrm{S} 4$, and iii) scenarios S5 and S6. This is due to the limited capabilities of these algorithms in producing new solutions on this type of problem.

Figures 4 and 5 illustrate the performance comparisons among the MTDA and the other algorithm schemes in terms of the allocation of pilgrims and the reservation space of Mina tents, respectively. The results demonstrated that the MTDA has the ability to generate the best distribution in all provided scenarios. The best achieved result is obtained in scenario 2, where $80 \%$ of the total pilgrims are allocated in $76.2 \%$ of the total space of Mina tents. The second best result is achieved by EPF algorithm scheme which has a good performance compared to other schemes, with $59.2 \%$ of total pilgrims are allocated in $56.3 \%$ of total space of Mina tents.

It should be noted that the unallocated groups should be distributed manually. The advantage of using the proposed MTDA is that the efforts spent on performing the manual distribution of Mina tents are minimized.

Table 6. Comparison of the MTDA scheme with other algorithm schemes.

\begin{tabular}{|c|c|c|c|c|c|c|c|}
\hline CGs & Methods & Sc1 & Sc2 & Sc3 & Sc4 & Sc5 & Sc6 \\
\hline \multirow{9}{*}{$\begin{array}{l}\text { Domestic } \\
\text { pilgrims }\end{array}$} & MTDA & $63.7 \%$ & $63.6 \%$ & $56.3 \%$ & $53.0 \%$ & $48.2 \%$ & $50.7 \%$ \\
\hline & $\mathrm{BF}$ & $26.6 \%$ & $26.6 \%$ & $28.0 \%$ & $28.0 \%$ & $27.5 \%$ & $27.5 \%$ \\
\hline & TBF1 & $16.6 \%$ & $18.2 \%$ & $18.3 \%$ & $17.0 \%$ & $21.9 \%$ & $20.0 \%$ \\
\hline & PF & $50.2 \%$ & $50.2 \%$ & $43.7 \%$ & $43.7 \%$ & $38.3 \%$ & $38.3 \%$ \\
\hline & TBF2 & $27.4 \%$ & $28.5 \%$ & $24.4 \%$ & $28.8 \%$ & $26.7 \%$ & $29.5 \%$ \\
\hline & TBF3 & $22.4 \%$ & $23.3 \%$ & $24.5 \%$ & $21.5 \%$ & $20.0 \%$ & $19.4 \%$ \\
\hline & $\mathrm{EBF}$ & $31.3 \%$ & $32.6 \%$ & $29.5 \%$ & $30.7 \%$ & $29.0 \%$ & $34.3 \%$ \\
\hline & EPF & $50.4 \%$ & $50.4 \%$ & $43.7 \%$ & $43.9 \%$ & $38.3 \%$ & $38.7 \%$ \\
\hline & $\operatorname{PrF}$ & $24.6 \%$ & $26.7 \%$ & $29.0 \%$ & $32.0 \%$ & $28.1 \%$ & $27.4 \%$ \\
\hline \multirow{9}{*}{$\begin{array}{l}\text { Arab } \\
\text { pilgrims }\end{array}$} & MTDA & $93.2 \%$ & $93.8 \%$ & $86.2 \%$ & $91.2 \%$ & $82.0 \%$ & $76.1 \%$ \\
\hline & $\mathrm{BF}$ & $69.3 \%$ & $69.3 \%$ & $75.3 \%$ & $75.3 \%$ & $50.7 \%$ & $50.7 \%$ \\
\hline & TBF1 & $80.8 \%$ & $81.2 \%$ & $78.0 \%$ & $83.3 \%$ & $79.6 \%$ & $80.0 \%$ \\
\hline & $\mathrm{PF}$ & $82.6 \%$ & $82.6 \%$ & $69.8 \%$ & $69.8 \%$ & $63.1 \%$ & $63.1 \%$ \\
\hline & TBF2 & $85.7 \%$ & $90.8 \%$ & $88.5 \%$ & $83.6 \%$ & $86.5 \%$ & $80.9 \%$ \\
\hline & TBF3 & $76.2 \%$ & $74.3 \%$ & $60.5 \%$ & $65.7 \%$ & $48.6 \%$ & $52.4 \%$ \\
\hline & EBF & $74.9 \%$ & $81.1 \%$ & $78.5 \%$ & $80.5 \%$ & $67.4 \%$ & $72.1 \%$ \\
\hline & EPF & $82.6 \%$ & $82.6 \%$ & $73.0 \%$ & $73.0 \%$ & $65.2 \%$ & $66.7 \%$ \\
\hline & $\operatorname{PrF}$ & $78.3 \%$ & $76.8 \%$ & $74.3 \%$ & $74.4 \%$ & $56.7 \%$ & $60.3 \%$ \\
\hline \multirow{7}{*}{$\begin{array}{l}\text { Asian } \\
\text { pilgrims } \\
\text { (none Arab) }\end{array}$} & MTDA & $76.6 \%$ & $81.3 \%$ & $61.6 \%$ & $66.6 \%$ & $58.8 \%$ & $63.3 \%$ \\
\hline & $\mathrm{BF}$ & $12.6 \%$ & $12.6 \%$ & $14.1 \%$ & $14.1 \%$ & $12.6 \%$ & $12.6 \%$ \\
\hline & TBF1 & $6.1 \%$ & $7.0 \%$ & $9.9 \%$ & $11.0 \%$ & $10.0 \%$ & $11.8 \%$ \\
\hline & $\mathrm{PF}$ & $44.8 \%$ & $44.8 \%$ & $31.7 \%$ & $31.7 \%$ & $27.9 \%$ & $27.9 \%$ \\
\hline & TBF2 & $23.7 \%$ & $23.7 \%$ & $26.9 \%$ & $28.7 \%$ & $29.9 \%$ & $29.5 \%$ \\
\hline & TBF3 & $24.8 \%$ & $26.6 \%$ & $29.6 \%$ & $31.5 \%$ & $33.0 \%$ & $37.5 \%$ \\
\hline & $\mathrm{EBF}$ & $16.3 \%$ & $18.1 \%$ & $17.8 \%$ & $21.4 \%$ & $14.4 \%$ & $17.6 \%$ \\
\hline
\end{tabular}




\begin{tabular}{|c|c|c|c|c|c|c|c|}
\hline & EPF & $49.2 \%$ & $52.1 \%$ & $37.9 \%$ & $41.7 \%$ & $31.2 \%$ & $36.3 \%$ \\
\hline & $\operatorname{PrF}$ & $12.7 \%$ & $12.5 \%$ & $13.8 \%$ & $14.3 \%$ & $12.3 \%$ & $12.5 \%$ \\
\hline \multirow{9}{*}{$\begin{array}{l}\text { African } \\
\text { pilgrims } \\
\text { (none Arab) }\end{array}$} & MTDA & $94.8 \%$ & $93.2 \%$ & $71.7 \%$ & $73.6 \%$ & $62.5 \%$ & $66.9 \%$ \\
\hline & $\mathrm{BF}$ & $20.4 \%$ & $20.4 \%$ & $22.5 \%$ & $22.5 \%$ & $20.7 \%$ & $20.7 \%$ \\
\hline & TBF1 & $8.0 \%$ & $9.7 \%$ & $10.3 \%$ & $16.6 \%$ & $16.7 \%$ & $16.7 \%$ \\
\hline & PF & $69.0 \%$ & $69.0 \%$ & $46.6 \%$ & $46.6 \%$ & $31.7 \%$ & $31.7 \%$ \\
\hline & TBF2 & $28.2 \%$ & $23.5 \%$ & $27.8 \%$ & $28.2 \%$ & $34.3 \%$ & $39.6 \%$ \\
\hline & TBF3 & $38.0 \%$ & $35.5 \%$ & $43.5 \%$ & $51.0 \%$ & $49.0 \%$ & $41.1 \%$ \\
\hline & $\mathrm{EBF}$ & $23.5 \%$ & $27.0 \%$ & $26.0 \%$ & $29.0 \%$ & $21.7 \%$ & $28.2 \%$ \\
\hline & EPF & $72.4 \%$ & $72.4 \%$ & $51.6 \%$ & $54.3 \%$ & $37.8 \%$ & $51.7 \%$ \\
\hline & $\operatorname{PrF}$ & $20.4 \%$ & $20.4 \%$ & $22.5 \%$ & $17.0 \%$ & $22.4 \%$ & $17.3 \%$ \\
\hline \multirow{9}{*}{$\begin{array}{l}\text { European } \\
\text { pilgrims }\end{array}$} & MTDA & $84.8 \%$ & $97.7 \%$ & $46.5 \%$ & $84.3 \%$ & $59.6 \%$ & $53.8 \%$ \\
\hline & $\mathrm{BF}$ & $7.6 \%$ & $7.6 \%$ & $7.1 \%$ & $7.1 \%$ & $30.8 \%$ & $30.8 \%$ \\
\hline & TBF1 & $0.0 \%$ & $0.0 \%$ & $0.0 \%$ & $0.0 \%$ & $0.0 \%$ & $5.8 \%$ \\
\hline & $\mathrm{PF}$ & $71.4 \%$ & $71.4 \%$ & $54.1 \%$ & $54.1 \%$ & $42.1 \%$ & $42.1 \%$ \\
\hline & TBF2 & $0.0 \%$ & $0.0 \%$ & $0.0 \%$ & $0.0 \%$ & $0.0 \%$ & $0.0 \%$ \\
\hline & TBF3 & $0.0 \%$ & $9.6 \%$ & $9.7 \%$ & $5.8 \%$ & $12.9 \%$ & $0.0 \%$ \\
\hline & $\mathrm{EBF}$ & $7.6 \%$ & $17.3 \%$ & $16.8 \%$ & $16.8 \%$ & $30.8 \%$ & $34.0 \%$ \\
\hline & EPF & $71.4 \%$ & $79.1 \%$ & $59.6 \%$ & $59.6 \%$ & $42.1 \%$ & $42.1 \%$ \\
\hline & $\operatorname{PrF}$ & $7.6 \%$ & $7.6 \%$ & $7.13 \%$ & $15.4 \%$ & $30.8 \%$ & $23.7 \%$ \\
\hline
\end{tabular}

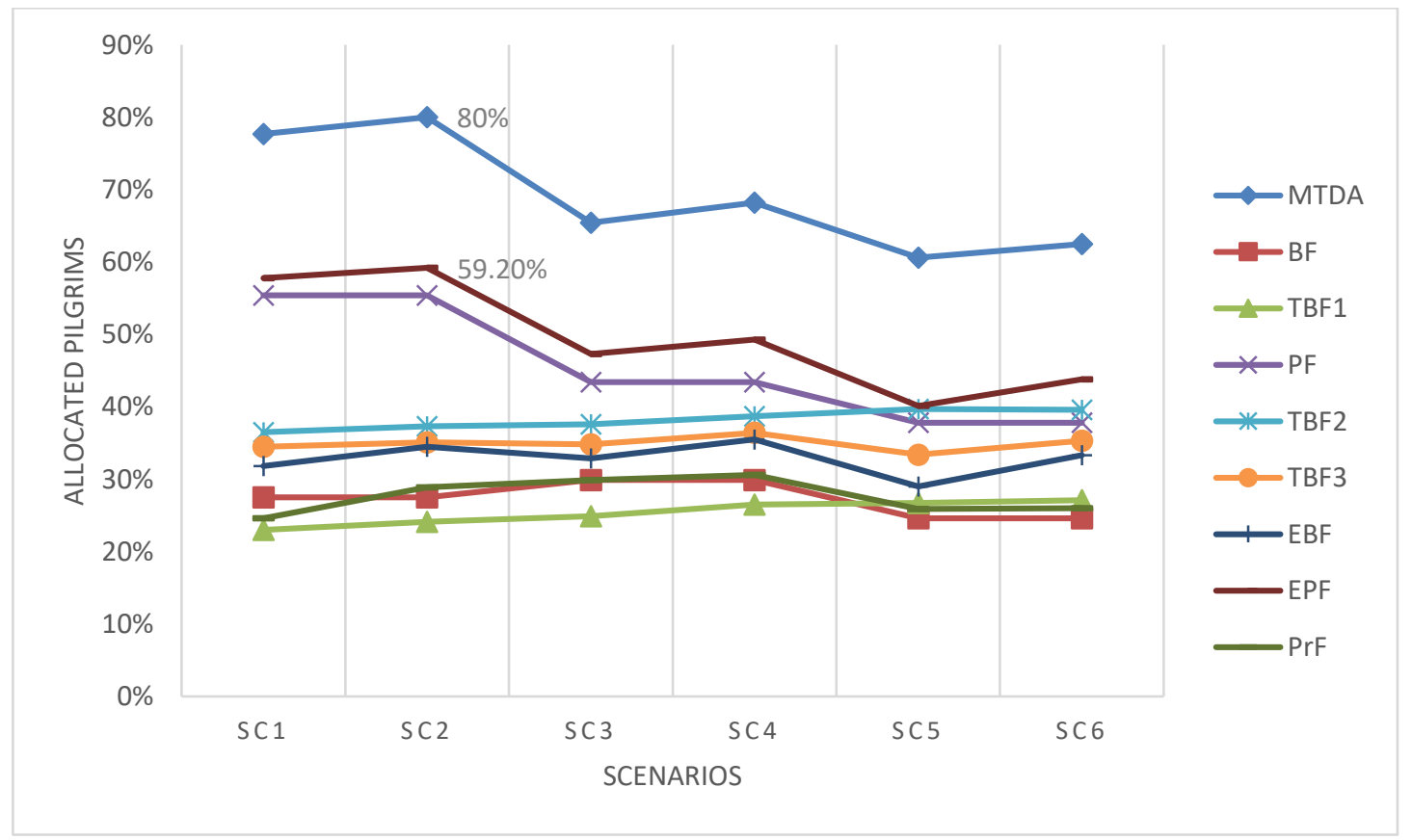

Fig. 4. Performance comparisons among the MTDA and the other algorithm schemes in terms of the allocation of pilgrims. 


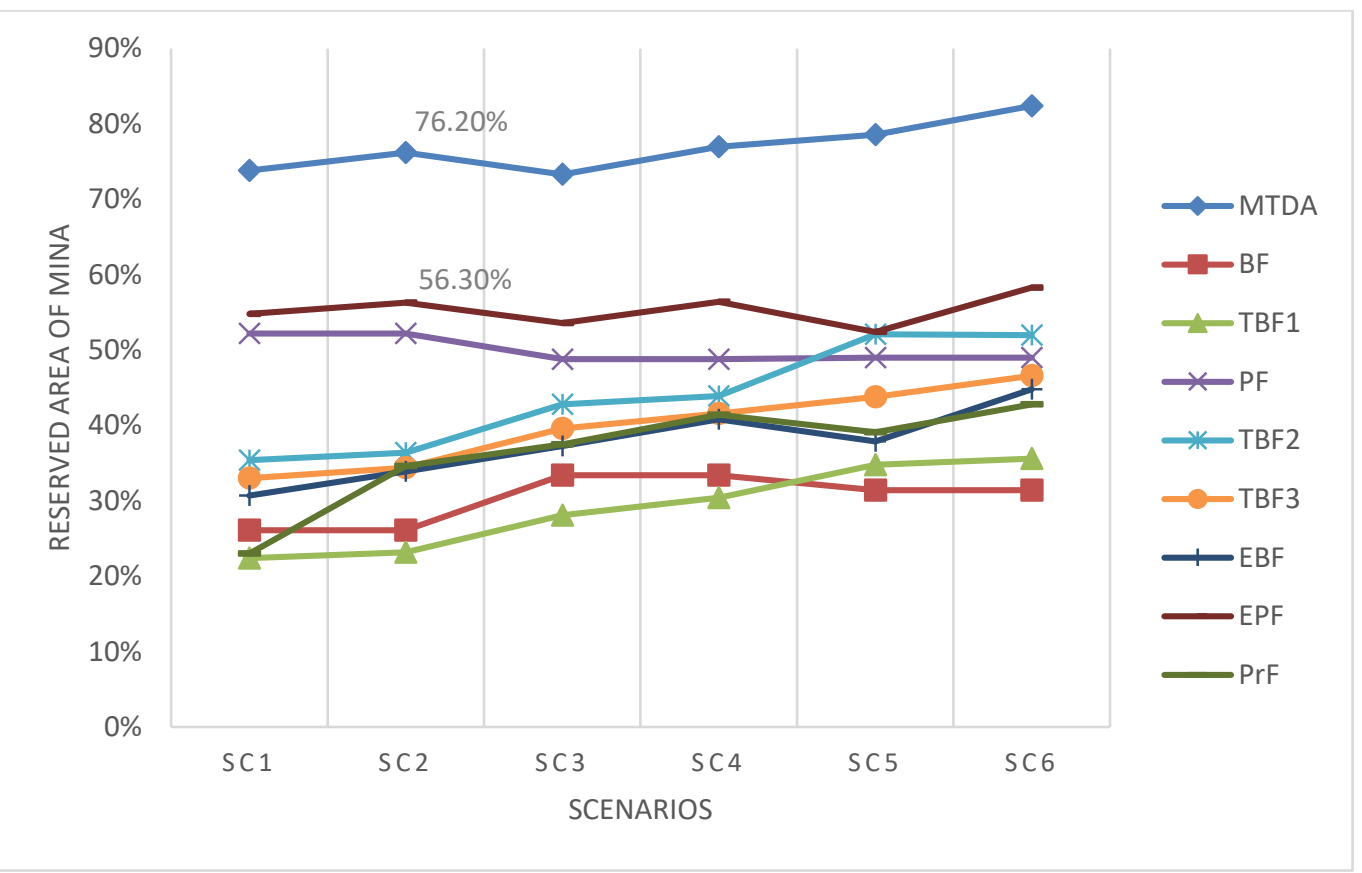

Fig. 5. Performance comparisons among the MTDA and the other algorithm schemes in terms of the reservation space of Mina area.

\section{Conclusion and Future Work}

An appropriate algorithm was designed and developed to optimize the distribution process of the Mina tents considering a set of constraints that are defined to regulate the distribution process.

The proposed MTDA was applied on six different scenarios and compared with eight algorithm schemes. Results show that the performance of the MTDA outperforms others in all experimental cases. However, the best achieved results by the MTDA was found in scenario 2 with $80 \%$ of pilgrims were allocated over $76.2 \%$ of the total available accommodation place of Mina area. Future work will be directed to improve the performance of the distribution process by employing the hyper-heuristic technique on the produced solutions, also more detailed analysis for the performance characteristics of the proposed allocation schemes will be studied (i.e., BF, TBF1, PF, TBF2, TBF3, $\mathrm{EBF}, \mathrm{EPF}$, and PrF).

\section{References}

[1] Khan, E. A. and Shambour, M. K. Y. (2017). An analytical study of mobile applications for Hajj and Umrah services. Applied computing and informatics.

[2] General Authority for statistics, "https://stats.gov.sa/en/news/280", last access (Nov, 2019).

[3] Edrees, Mohammed (2013), “An Urban Study of Crowdness in Muna and Jamarat Area", Journal of King Abdulaziz University: Environmental Design Sciences, 7: 159-192.

[4] Holy Makkah Municipality, "https://holymakkah.gov.sa", last access (Nov, 2019).

[5] Katoh, N. (2009). Combinatorial optimization algorithms in resource allocation problems. Encyclopedia of Optimization, 382-387.

[6] Katoh N., Shioura A. and Ibaraki T. (2013) Resource Allocation Problems. In: Pardalos P., Du DZ., Graham R. (eds). Handbook of Combinatorial Optimization. Springer, New York, NY.

[7] Reichman, A., Wayer, S. and Moreno, M. P. (2018, December). Resource Allocation in Wireless Mesh Networks. In: 2018 IEEE International Conference on 
the Science of Electrical Engineering (ICSEE) (pp. 15). IEEE.

[8] Maleki, E. N. and Mirjalily, G. (2019). Cross layer resource allocation for fault-tolerant topology control in wireless mesh networks based on genetic algorithm. EURASIP Journal on Wireless Communications and Networking, 2019 (1): 13.

[9] Nguyen, Q. H. and Pham, T. A. T. (2018, November). Studying and developing a resource allocation algorithm in Fog computing. In: 2018 International Conference on Advanced Computing and Applications (ACOMP) (pp. 76-82). IEEE.

[10] Gupta, H., Vahid Dastjerdi, A., Ghosh, S. K. and Buyya, R. (2017). iFogSim: A toolkit for modeling and simulation of resource management techniques in the Internet of Things, Edge and Fog computing environments. Software: Practice and Experience, 47(9): 1275-1296.
[11] Santos, I. L., Pirmez, L., Delicato, F. C., Oliveira, G. M., Farias, C. M., Khan, S. U. and Zomaya, A. Y. (2019). Zeus: A resource allocation algorithm for the cloud of sensors. Future Generation Computer Systems, 92: $564-581$.

[12] Gülpınar, N., Çanakoğlu, E. and Branke, J. (2018). Heuristics for the stochastic dynamic task-resource allocation problem with retry opportunities. European Journal of Operational Research, 266(1): 291-303.

[13] Lee, D. H. (2018). Resource-based task allocation for multi-robot systems. Robotics and Autonomous Systems, 103: 151-161.

[14] Sun, C., Wang, X. and Liu, J. (2017, October). Evolutionary game theoretic approach for optimal resource allocation in multi-agent systems. In: 2017 Chinese Automation Congress (CAC) (pp: 5588-5592). IEEE.). 


\section{منهج إرشادي لتوزيع الحجاج على خيام منى محمد خالد شمبور و عصام خان}

معهد خادم الحردين الثرنين لأبحاث الحج والعدرة، جامعة أم القرى، مكة المكرمة، المدلكة العربية السعودية myshambour@uqu.edu.sa

المستخلص. في كل عام، يجتمع أكثر من مليوني مسلم إلى المدينة المقدسة، مكة، لأداء فريضة الحج. وكأحد مناسك الحج، هو قضاء ليلتين أو ثلاث ليال في منى، أحد الأماكن المقدسة. وإن توزيع الحجاج المسلمين في منى على عدد محدود من الخيام، مع مراعاة أنواع هوداع مختلفة من القيود، من المشاكل التي تواجهنا في عالمنا المعاصر • في هذه الورقة، تم اقتراح خوارزمية قائمة على الاستدلال، تسمى خوارزمية توزيع خيام منى (MTDA)، في محاولة للاستفادة بشكل أفضل من السعة المتاحة لمنطقة منى، مع الاستخدام الأمثل للموارد المتاحة. تقوم MTDA بمعالجة سبع دوال أثناء عملية البحث للعثور على سكن مناسب للحجاج في الخيام المتوفرة في منى. وكثفت النتائج التجريبية أن MTDA تحقق أداءً أفضل مقارنة بثمانية برامج خوارزمية بجميع الحالات التجريبية. كما تم الحصول على أفضل نتيجة لـ MTDA من خلال

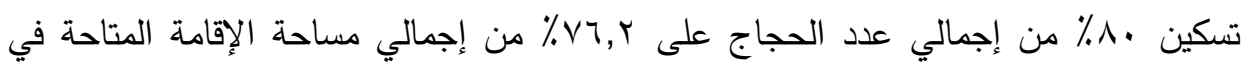
منطقة منى. كلمات منتاحية : مناسك الحج، توزيع، قيود، إرشادي. 
